\title{
PENGARUH KONDISI MODAL KERJA TERHADAP PROFITABILITAS (Studi Empiris : Pada Perusahaan Manufaktur Yang Terdaftar pada BEI Katagori Saham LQ 45 Periode 2007 Sampai Dengan 2011 )
}

\author{
Hermansyah \\ Program Studi Magister Manajemen \\ Universitas Persada Indonesia Y.A.I Jakarta
}

\begin{abstract}
ABSTRAKS, Penelitian ini adalah untuk menguji secara empiris pengaruh kondisi modal kerja yang didasarkan pada rasio keuangan yang berpengaruh terhadap profitabilitas saham LQ 45 sektor manufaktur pada Bursa Efek Indonesia baik secara parsial maupun simultan. Rasio keuangan yang digunakan untuk mengetahui kondisi modal kerja adalah current ratio, working capital turn over ratio, current assets to total assets ratio, dan current liabilities to total assets ratio sebagai variabel dependent dalam hal ini adalah return on investment.

Data penelitian ini menggunakan sepuluh perusahaan manufaktur yang masuk ke dalam kategori saham LQ 45 yang terdaftar di Bursa Efek Indonesia. Data yang digunakan adalah data laporan keuangan yang berakhir tahun 2007 sampai dengan 2011. Hasil penelitian menunjukan bahwa secara simultan current ratio, working capital turn over ratio, current assets to total assets ratio, dan current liabilities to total assets ratio berpengaruh terhadap return on investment pada tingkat alpha $(\alpha)=0.05(\operatorname{sig} 0.071)$.
\end{abstract}

Kata Kunci : current ratio, working capital turn over ratio, current assets to total assets ratio, current liabilities to total assets ratio, dan return on investment.

ABSTRACT, The purpose of this research is empirically to examine the effect of working capital which is based on financial ratio and will give influence partially or simultaneously to the manufacturing stocks of LQ45 at Indonesia Stock Exchange. Financial ratios which are used to determine the condition of working capital are current ratio, working capital turnover ratio, current assets to total assets ratio and current liabilities to total assets ratio which are used as dependent variable is return on investment.

The data research collected from 10 manufacture's company in LQ45 stocks category and listed in Indonesia Stock Exchange. Data collected from financial report from year ended 2007 to 2011. The final results shows that current ratio, working capital turnover ratio, current assets to total assets ratio, and current liabilities to total assets ratio are influence simultaneously to return of investment at the level of alpha $(a)=0.05(\operatorname{sig} 0.071)$

Keywords : current ratio, working capital turn over ratio, current assets to total assets ratio, current liabilities to total assets ratio, and return on investment.

\section{PENDAHULUAN}

\section{Latar Belakang}

Kinerja keuangan menyangkut keberhasilan perusahaan dalam mencapai tujuan yang telah ditetapkan menggunakan beberapa kriteria diantaranya ROI (Return on Invesment).
Return On Invesment (ROI) menunjukkan rasio yang digunakan oleh perusahaan untuk mengukur kemampuan perusahaan di dalam menghasilkan laba selama periode tertentu. Jumlah keuntungan (laba) yang diperoleh secara teratur serta kecenderungan keuntungan yang meningkat merupakan faktor yang sangat penting dalam menilai rentabilitas 
TRANSPARANSI

Jurnal Ilmiah Ilmu Administrasi

ISSN 2085-1162

atau profitabilitas suatu perusahaan. Bagi pimpinan, profitabilitas dapat digunakan sebagai tolok ukur untuk mengetahui berhasil atau tidaknya suatu perusahaan yang dipimpinnya, sedangkan bagi penanam modal dapat digunakan sebagai tolok ukur prospek modal yang ditanamkan dalam perusahaan tersebut.

Kegiatan kegiatan yang dibiayai oleh modal kerja antara lain adalah pembelian material/ bahan baku, upah dan gaji karyawan serta berbagai macam biaya yang diharapkan dapat kembali dalam waktu singkat melalui hasil penjualan. Uang yang masuk dan bersumber dari hasil penjualan barang tersebut akan dikeluarkan kembali guna membiayai operasi perusahaan selanjutnya. Dengan demikian dana tersebut akan berputar secara terus menerus setiap periodenya sepanjang hidup perusahaan

\section{Perumusan Masalah}

Masalah yang akan diteliti selanjutnya dapat dirumuskan dalam bentuk pertanyaan sebagai berikut :

1. Apakah ada pengaruh Current Ratio terhadap Rasio Return On Invesment pada perusahaan katagori LQ 45 yang terdaftar di Bursa Efek Indonesia?

2. Apakah ada pengaruh Working Capital Turn Over Ratio terhadap Rasio Return On Investment pada perusahaan katagori LQ 45 yang terdaftar di Bursa Efek Indonesia?

3. Apakah ada pengaruh Current Assets to Total Assets Ratio terhadap Rasio Return On Investment pada perusahaan katagori LQ 45 yang terdaftar di Bursa Efek Indonesia?

4. Apakah ada pengaruh Current Liabilities to Total Assets Ratio terhadap Rasio Return On Invesment pada perusahaan katagori LQ 45 yang terdaftar di Bursa Efek Indonesia ?

5. Apakah ada pengaruh Current Ratio, Working Capital Turn Over Ratio, Current Asset to Total Asset Ratio, dan Current Liabilities to Total Assets Ratio secara bersama-sama (simultan) terhadap Rasio Return On Invesment pada perusahaan katagori LQ 45 yang terdaftar di Bursa Efek Indonesia?

\section{Tujuan Penelitian}

Berdasarkan rumusan masalah diatas penelitian ini bertujuan untuk mengetahui seberapa besar :

1. Pengaruh Current Ratio terhadap Rasio Return On Investment pada perusahaan katagori LQ 45 yang terdaftar di Bursa Efek Indonesia.

2. Pengaruh Working Capital Turn Over Ratio terhadap Rasio Return On Investment pada perusahaan katagori LQ 45 yang terdaftar di Bursa Efek Indonesia.

3. Pengaruh Current Assets to Total Assets Ratio terhadap Rasio Return On Investment pada perusahaan katagori LQ 45 yang terdaftar di Bursa Efek Indonesia.

4. Pengaruh Current Liabilities to Total Assets Ratio terhadap Rasio Return On Invesment pada perusahaan katagori LQ 45 yang terdaftar di Bursa Efek Indonesia.

5. Pengaruh Current Ratio, Working Capital Turn Over Ratio, Current Asset to Total Asset Ratio, dan Current Liabilities to Total Assets Ratio secara bersama-sama ( simultan ) terhadap Rasio Return On Investment pada perusahaan katagori LQ 45 yang terdaftar di Bursa Efek Indonesia.

\section{TINJAUAN PUSTAKA}

\section{Profitabilitas}

Pengertian profitabilitas suatu perusahaan merupakan kemampuan suatu perusahaan dalam menghasilkan laba selama periode tertentu pada tingkat penjualan, asset dan modal saham tertentu (Bambang Riyanto, 2007:35). 
Hermansyah, Pengaruh Kondisi Modal Kerja Terhadap Profitabilitas...

Profitabilitas adalah rasio yang menunjukkan keberhasilan perusahaan di dalam menghasilkan keuntungan (Robert Ang, 2007:18). Selain itu, profitabilitas adalah rasio yang mengukur efektifitas manajemen yang ditunjukkan oleh laba yang dihasilkan dari penjualan investasi perusahaan (J. Fred \& Thomas. E. Copeland, 2010:23). Dalam penelitian pengukuran profitabilitas perusahaan yang digunakan adalah ROI digunakan untuk mengukur efektivitas perusahaan didalam menghasilkan keuntungan dengan memanfaatkan aktiva yang dimilikinya.

\section{Modal Kerja}

Modal kerja merupakan kekayaan/aktiva yang diperlukan oleh perusahaan untuk menghasilkan barang/jasa atau untuk membelanjai kegiatan perusahaan sehari-hari, dan selalu berputar dalam periode tertentu dalam menopang usaha perusahaan. (Riyanto, 2007:58). Konsep yang mendasari manajemen modal kerja yang sehat adalah dua keputusan yang menyangkut persoalan dasar perusahaan, yaitu tingkat investasi optimal dalam aktiva lancar dan perpaduan yang sesuai antara pendanaan jangka pendek dan pendanaan jangka panjang yang digunakan untuk mendukung investasi dalam aktiva lancar.Keputusankeputusan tersebut mempengaruhi hasil yang diharapkan yaitu profitabilitas dan risiko yang dihadapi.

Sawir (2010:138) menjelaskan ada 3 (tiga) pilihan kebijakan bagi manajemen perusahaan untuk membelanjai modal kerjanya, yaitu :

1. Kebijakan Modal Kerja Konservatif.

Kebijakan modal kerja konservatif adalah kebijakan dimana perusahaan memodali sebagian modal kerja variabelnya dengan modal permanen, sedangkan modal kerja permanen dan aktiva tetap dibelanjai oleh modal permanen.

2. Kebijakan Modal Kerja Moderat Perusahaan dapat pula mengambil kebijakan modal kerja moderat dalam membelanjai modal kerjanya dimana dalam hal ini modal kerja variabel yang dimiliki oleh perusahaan dimodali dengan sumber dana jangka pendek dan modal kerja permanen serta aktiva tetap dimodali dari sumber dana jangka panjang.

3. Kebijakan Modal Kerja Agresif

Kebijakan modal kerja agresif adalah bila semua modal kerja dibelanjai dengan modal kerja jangka pendek, tetapi sebahagian dari modal kerja permanennya di belanjai dengan sumber modal kerja jangka pendek.

\section{Hubungan Current Ratio terhadap ROI}

Current Ratio adalah perbandingan antara aktiva lancar dengan hutang lancar. Rasio ini menunjukkan berapa besar hutang lancar yang dijamin oleh aktiva lancar.

Semakin besar rasio ini maka semakin kemampuan perusahaan untuk melunasi kewajiban jangka pendeknya. Salah satu unsur kebijakan modal kerja berasal dari aktiva lancar berupa kas, piutang dan persediaan. Mengelola modal kerja berarti

\section{Hubungan Working Capital Turnover Ratio terhadap Profitabilitas (ROI)}

Rasio perputaran modal kerja merupakan perbandingan antara penjualan dengan jumlah keseluruhan aktiva lancar yang dimiliki suatu perusahaan pada suatu periode tertentu. (Abdul Raheman \& Mahamed, 2007:71), Semakin besar rasio perputaran modal kerja maka semakin baik suatu perusahan dimana persentase modal kerja yang ada mampu menghasilkan jumlah penjualan tertentu. Selain itu semakin besar rasio ini menunjukkan efektifnya pemanfaatan modal kerja yang tersedia dalam meningkatkan profitabilitas perusahaan.

Tingkat perputaran modal kerja yang tinggi akan menyenangkan kreditor jangka pendek. Mereka akan memperoleh kepastian bahwa modal kerja berputar dengan keceptan tinggi dan utang akan 


\section{TRANSPARANSI}

Jurnal Ilmiah Ilmu Administrasi

ISSN 2085-1162

segera dapat dibayar meski dalam kondisi operasi yang sulit sehingga meningkatkan profitabilitas perusahaan. Suatu perusahaan dikatakan memiliki profitabilitas tinggi artinya bahwa modal yang besar, efektivitas juga akan tinggi. Tetapi modal yang besar belum tentu perusahaan memperoleh profitabilitas yang tinggi. Hal ini tergantung dari penggunaan penggunaan modal kerja apakah efektif dan efisien atau tidak. Modal kerja yang selalu berputar akan mempengaruhi arus dana dalam perusahaan.

Apabila perputaran modal kerja mengalami peningkatan setiap tahunnya, berarti arus dana yang kembali ke perusahaan akan semakin lancar. Begitu pula sebaliknya, semakin rendah tingkat perputaran modal kerja, semakin panjang waktu terikatnya dana yang berarti pengelolaan modal kerja kurang efektif dan dan cenderung menurunkan profitabilitasnya.

\section{Hubungan Current Assets to Total Assets Ratio terhadap Profitabilitas (ROI)}

Rasio jumlah aktiva lancar terhadap total aktiva merupakan perbandingan jumlah aktiva lancar terhadap total aktiva yang terdapat diperusahaan yang dinyakan dalam persen (Sawir, 2010 :144). Dapat dihitung dengan rumus :

Rasio Jumlah Aktiva Lancar Terhadap Total Aktiva $=\frac{\text { Jumlah Aktiva Lancar }}{\text { Total Aktiva }}$

Semakin besar rasio semakin baik karena menunjukkan tersedianya kas, piutang dan persediaan yang merupakan harta lancar yang paling likuid dibanding dengan keseluruhan aktiva yang dimiliki perusahaan. Adanya aktiva yang likuid dapat digunakan sewaktu - waktu dapat membiayai kebutuhan operasional perusahaan dalam rangka menghasilkan laba.

\section{Hubungan Current Liabilities to Total Assets Ratio terhadap Profitabilitas (ROI)}

Rasio jumlah hutang lancar terhadap total aktiva merupakan perbandingan jumlah hutang lancar terhadap total aktiva yang terdapat diperusahaan yang dinyatakan dalam persen (Barlian \& Sundjaja, 2009:78). Dapat dihitung dengan rumus:

Rasio Hutang Lancar Terhadap Total Aktiva

$$
=\frac{\text { Jumlah Hutang Lancar }}{\text { Total Aktiva }}
$$

Rasio ini menekankan pentingnya pendanaan hutang bagi perusahaan dengan jalan menunjukkan besarnya aktiva perusahaan yang dibiayai dengan hutang jangka pendek. Semakin besar persentase pendanaan berasal dari ekuitas pemegang saham maka dari sudut kreditur bermakna makin besar perlindungan bagi pemberi pinjaman. Semakin tinggi rasio ini maka

Rasio Jumlah Aktiva Lancar terhadap Total Aktiva $=\frac{\text { Jumlah aktiva Lancar }}{\text { Total Aktiva }}$

dapat mengganggu capaian profitabilitas perusahaan. Semakin kecil rasio ini maka semakin baik atau semakin kecil risiko keuangan.

\section{Hipotesis}

Berdasarkan perumusan masalah dan kerangka pemikiran, maka dapat dikemukakan hipotesis sebagai berikut:

1. Terdapat pengaruh Current Ratio terhadap Return On Investment Ratio pada perusahaan katagori LQ 45 yang terdaftar di Bursa Efek Indonesia.

2. Terdapat pengaruh Working Capital Turn Over Ratio terhadap Return On Investment Ratio pada perusahaan katagori LQ 45 yang terdaftar di Bursa Efek Indonesia. 
Hermansyah, Pengaruh Kondisi Modal Kerja Terhadap Profitabilitas...

3. Terdapat pengaruh Current Assets to Total Assets Ratio terhadap Return On Investment Ratio pada perusahaan katagori LQ 45 yang terdaftar di Bursa Efek Indonesia.

4. Terdapat pengaruh Current Liablities to Total Assets Ratio terhadap Return On Investment Ratio pada perusahaan katagori LQ 45 yang terdaftar di Bursa Efek Indonesia.
5. Terdapat pengaruh Current Ratio, Working Capital Turn Over Ratio, Current Assets to Total Assets Ratio. Dan Current Liabilities to Total Assets Ratio secara bersama-sama (simultan) terhadap Return On Investment Ratio pada perusahaan katagori LQ 45 yang terdaftar di Bursa Efek Indonesia.

\section{Gambar 1. Kerangka Hipotesis}

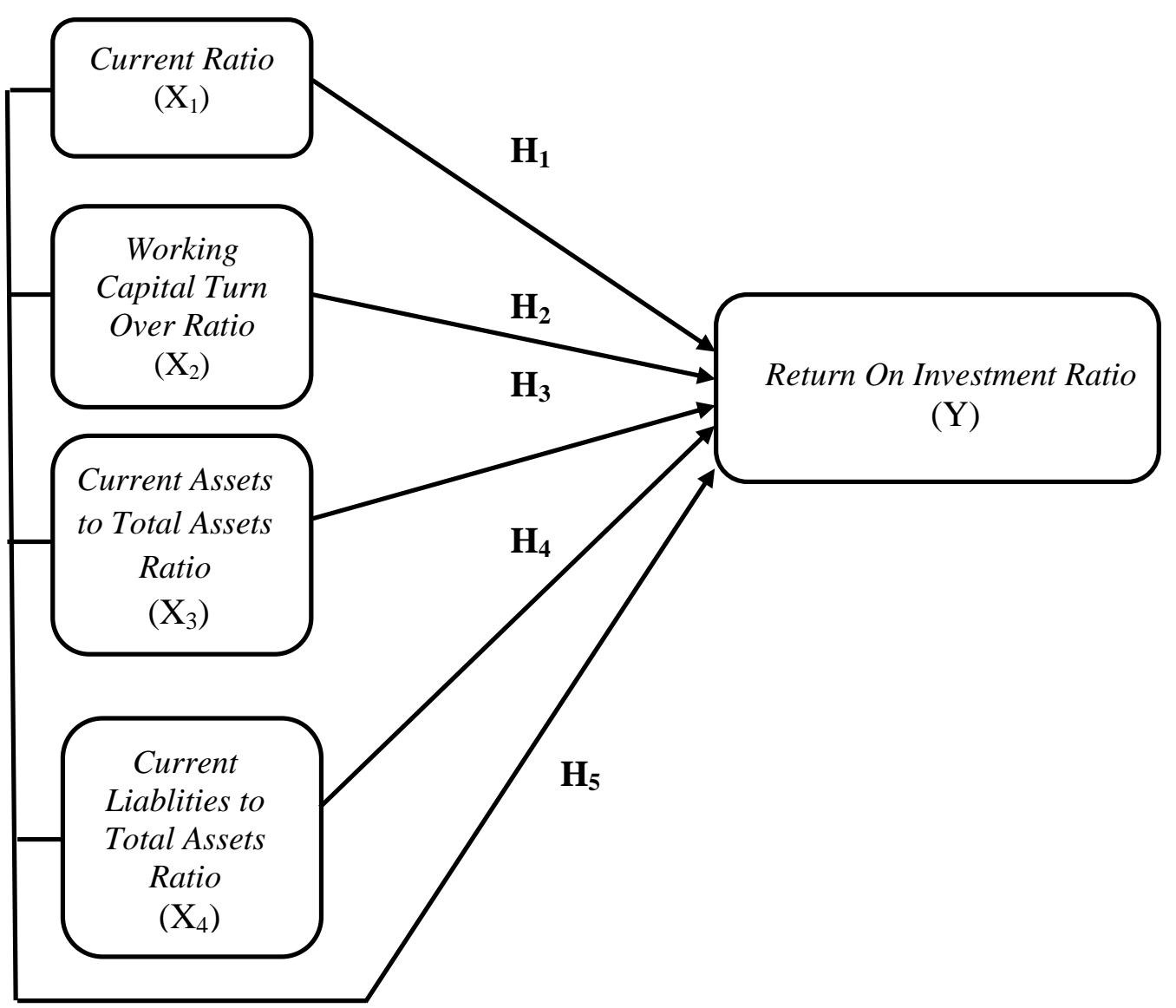


TRANSPARANSI

Jurnal Ilmiah Ilmu Administrasi

ISSN 2085-1162

\section{METODE PENELITIAN}

\section{Desain Penelitian}

Sumber data yang diambil oleh peneliti dalam penelitian merupakan Data Sekunder (Secondary Data). Penelitian ini menggunakan jenis penelitian study event, dimana populasi dari penelitian ini sudah ditentukan yaitu semua perusahaan listing di Bursa Efek Indonesia dalam perusahaan manufaktur kelompok LQ 45 dari priode $2007-2011$.

Karena saham - saham yang tergabung dalam Kelompok LQ 45 ini sifatnya berubah setiap 6 bulan sekali, oleh sebab itu dalam penelitian ini hanya akan meneliti saham - saham yang masih terdaftar pada Kelompok LQ-45 dan konsisten ada selama periode penelitian (tahun 2007 sampai dengan tahun 2011).

Kriteria untuk memilih sampel dalam penelitian ini ditentukan sebagai berikut : a. Telah terdaftar di BEI terhitung setahun sebelum periode waktu penelitian ini.

b. Termasuk dalam saham yang tergabung pada kelompok LQ 45 selama periode penelitian berturutan.

c. Perusahaan yang dijadikan sampel adalah perusahaan dalam industri yang sejenis yakni perusahaan yang masuk dalam kategori industri manufaktur.

Berdasarkan pada kriteria ini, jumlah perusahaan manufaktur yang terdaftar di BEI pada Kelompok LQ-45 dan konsisten ada selama periode penelitian (tahun 2007 sampai dengan tahun 2011) sebanyak 10 perusahaan. Sehingga diperoleh jumlah sampel dalam penelitian ini sebanyak 10 perusahaan manufaktur. Adapun ke sepuluh perusahaan tersebut dapat dijabarkan sebagai berikut :

Tabel 1.

Perusahaan Manufaktur Yang Masuk Dalam Daftar Saham LQ45 Periode Tahun 2007 Sampai Dengan Tahun 2011

\begin{tabular}{|c|c|c|}
\hline No & Kode Saham & Nama Emiten LQ45 Kategori Manufaktur \\
\hline 1 & INTP & Indocement Tunggal Prakarsa Tbk \\
\hline 2 & SMCB & Holcim Indonesia Tbk \\
\hline 3 & SMGR & Semen Gresik Tbk \\
\hline 4 & CPIN & Charoen Pokphand Indonesia Tbk \\
\hline 5 & ASII & Astra International Tbk \\
\hline 6 & GJTL & Gajah Tunggal Tbk \\
\hline 7 & INDF & Indofood Sukses Makmur Tbk \\
\hline 8 & GGRM & Gudang Garam Tbk \\
\hline 9 & KLBF & Kalbe Farma Tbk \\
\hline 10 & UNVR & Unilever Indonesia Tbk \\
\hline
\end{tabular}

\section{Variabel Penelitian}

Variabel terikat yang digunakan dalam penelitian ini Profitabilitas (Return On Investment Ratio) dengan menggunakan skala rasio. ROI digunakan untuk mengukur efektivitas perusahaan didalam menghasilkan keuntungan dengan memanfaatkan aktiva yang dimilikinya. Rasio ini merupakan rasio yang terpenting diantara rasio profitabilitas yang ada. sedangkan variabel bebas adalah current ratio, working capital turn over ratio, 
Hermansyah, Pengaruh Kondisi Modal Kerja Terhadap Profitabilitas...

current assets to total assets ratio, dan current liabilities to total assets ratio.

\section{Metode Analisis data}

Rancangan analisis merupakan langkah - langkah yang dilakukan dalam menganalisis data dengan menggunakan soft ware eviews versi 7.2 dengan tekhnik estimasi data panel. Adapun model tekhnik estimasi yang dihasilkan antara lain adalah

\section{Common Effect Model ( Pooled Least Square )}

Tekhnik ini sama seperti dengan membuat regresi dengan data cross section atau time series. Akan tetapi untuk data panel sebelum membuat regresi terlebih dahulu kita harus menggabungkan data cross section dengan data time series (Pooled data). Kemudian data gabungan ini diperlakukan sebagai suatu kesatuan pengamatan untuk mengestimasi model dengan menggunakan OLS (ordinary least square). Metode ini dikenal dengan estimasi common effect. Kelemahan common effect adalah ketidaksesuaian model dengan keadaan yang sesungguhnya. Kondisi tiap objek saling berbeda, bahkan satu objek pada suatu waktu akan sangat berbeda dengan kondisi objek tersebut pada waktu yang lain ( Wing Wahyu Winarno, 2011 : 9.15)

\section{Fixed Effect Model ( FEM)}

Fixed effect diperlukan untuk menunjukan perbedaan konstanta antar objek, meskipun dengan koefisien regresi yang sama. Efek tetap disini maksudnya adalah bahwa suatu objek memilki konstanta yang tetap besarnya untuk berbagai periode waktu. Demikian juga dengan koefisien regresinya, tetap besarnya dari waktu ke waktu ( Wing Wahyu Winarno, 2011 : 9.15). dan dalam pendekatan common effect ini untuk membedakan satu objek dengan objek lainnya digunakan variabel semu (dummy variable)

\section{Random Effect Model ( REM )}

Random Effect Model ( REM ) digunakan untuk mengatasi kelemahan fixed effect model yang menggunakan dummy variable sehingga model mengalami ketidakpastian. Tanpa menggunakan dummy variable, random effect model menggunakan residual yang diduga memiliki hubungan antar waktu dan antar objek. Namun untuk menganalisis random effect model ada syarat dimana objek data silang harus lebih besar dari pada banyaknya koefisien ( Wing Wahyu Winarno, 2011 : 9.17).

\section{ANALISIS DAN PEMBAHASAN}

\section{Deskriptif Data Penelitian}

Untuk memperoleh gambaran secara menyeluruh tentang variabelvariabel yang digunakan dalam penelitian ini baik variabel terikat maupun variabel bebas, maka dilakukan terlebih dahulu analisis secara statistik deskriptif yang mencakup nilai rata-rata (mean), standar deviasi, dan nilai ekstrim (nilai maksimum dan nilai minimum). Berikut ini rangkuman data statistik deskriptif dari variabel-variabel yang di gunakan dalam penelitian ini seperti yang ditunjukkan pada Tabel : 
Tabel 2 Statistik Deskriptif Dari Variabel - Variabel Penelitian

\begin{tabular}{|c|c|c|c|c|c|}
\hline & Y? & $\mathrm{X} 1$ ? & $\mathrm{X} 2 ?$ & $\mathrm{X} 3 ?$ & $\mathrm{X} 4 ?$ \\
\hline Mean & 20.83740 & 220.8972 & 355.4134 & 48.09114 & 26.42048 \\
\hline Median & 18.38000 & 180.1600 & 287.1105 & 43.85176 & 24.02658 \\
\hline Maximum & 56.76000 & 696.6400 & 999.2495 & 75.90423 & 54.88950 \\
\hline Minimum & 1.660000 & 29.17000 & 112.2387 & 4.718628 & 7.583974 \\
\hline Std. Dev. & 14.03973 & 132.6683 & 225.6194 & 18.19036 & 12.33767 \\
\hline Skewness & 0.973961 & 1.429229 & 1.465306 & -0.179190 & 0.660800 \\
\hline Kurtosis & 3.244921 & 5.285098 & 4.505281 & 2.234119 & 2.536351 \\
\hline Jarque-Bera & 8.029965 & 27.90095 & 22.61324 & 1.489605 & 4.086660 \\
\hline Probability & 0.018043 & 0.000001 & 0.000012 & 0.474828 & 0.129596 \\
\hline Sum & 1041.870 & 11044.86 & 17770.67 & 2404.557 & 1321.024 \\
\hline Sum Sq. Dev. & 9658.583 & 862443.5 & 2494302. & 16213.58 & 7458.687 \\
\hline Observations & 50 & 50 & 50 & 50 & 50 \\
\hline Cross sections & 10 & 10 & 10 & 10 & 10 \\
\hline
\end{tabular}

\section{Uji Hausman}

Tabel 3 Hasil Uji Hipotesis Dengan Metode Hausman Test

Correlated Random Effects - Hausman Test

Pool: EMITEN

Test cross-section random effects

\begin{tabular}{lrcc}
\hline \hline Test Summary & Chi-Sq. Statistic & Chi-Sq. d.f. & Prob. \\
\hline \hline $\begin{array}{l}\text { Cross-section } \\
\text { random }\end{array}$ & 12.394160 & 4 & 0.0146 \\
\hline \hline
\end{tabular}


Hermansyah, Pengaruh Kondisi Modal Kerja Terhadap Profitabilitas...

Berdasarkan tabel Haussman test cross section random effects di atas, diperoleh nilai probabilita $=0.0146<0.05$, artinya hipotesis $\mathrm{H}_{0}$ ditolak dan $\mathrm{H}_{1}$ diterima atau pendekatan model yang terbaik adalah Fixed Effect Model (FEM). Berdasarkan pada uji Haussman, maka dapat ditentukan bahwa model yang terbaik untuk menentukan $\mathrm{Y}$ terhadap 10 perusahaan yang terdaftar di BEI pada kurun waktu 2007 - 2011 adalah Fixed Effect Model (FEM).

\section{Uji Hipotesis}

Tabel 4 Hasil Uji Hipotesis

Dependent Variable: Y?

Method: Pooled Least Squares

Date: 07/26/13 Time: 17:24

Sample: 15

Included observations: 5

Cross-sections included: 10

Total pool (balanced) observations: 50

\begin{tabular}{crrrr}
\hline \hline Variable & Coefficient & Std. Error & t-Statistic & Prob. \\
\hline \hline C & 22.43253 & 7.860997 & 2.853649 & 0.0071 \\
X1? & -0.008352 & 0.019151 & -0.436106 & 0.6654 \\
X2? & 0.008232 & 0.004889 & 1.683715 & 0.1009 \\
X3? & 0.272853 & 0.159431 & 1.711422 & 0.0956 \\
X4? & -0.597933 & 0.198181 & -3.017104 & 0.0047 \\
Fixed Effects (Cross) & & & \\
_ASTRA-C & 0.713785 & & & \\
_CHAROEN_C & 5.263621 & & & \\
_GAJAH_C & -14.60699 & & & \\
_GUDANGGARAM-C & -9.852390 & & & \\
_HOLCIM-C & -12.96825 & & & \\
_INDOCEMENT-C & -2.295013 & & & \\
_INDOFOOD_C & -6.618129 & & & \\
_KALBE-C & -7.569511 & & & \\
_SEMENGRESIK-C & 4.274302 & & & \\
_UNILEVER-C & 43.65858 & & & \\
\hline \hline
\end{tabular}

Effects Specification

Cross-section fixed (dummy variables)

\begin{tabular}{lrll}
\hline \hline R-squared & 0.862821 & Mean dependent var & 20.83740 \\
Adjusted R-squared & 0.813284 & S.D. dependent var & 14.03973 \\
S.E. of regression & 6.066654 & Akaike info criterion & 6.674987 \\
Sum squared resid & 1324.954 & Schwarz criterion & 7.210354 \\
Log likelihood & -152.8747 & Hannan-Quinn criter. & 6.878858 \\
F-statistic & 17.41776 & Durbin-Watson stat & 1.931941 \\
Prob(F-statistic) & 0.000000 & & \\
\hline
\end{tabular}




\section{TRANSPARANSI}

Jurnal Ilmiah Ilmu Administrasi

ISSN 2085-1162

Berdasarkan tabel hasil analisis data model fixed effect di atas, maka model persamaan regresi dapat dituliskan sebagai berikut:

$$
Y_{i t}=22,433-0,008 X_{1 i t}+0,008 X_{2 i t}+0,273 X_{3 i t}-0,598 X_{4 i t}
$$

a) Koefisien Determinasi $\left(R^{2}\right)$

Berdasarkan model regresi fixed effect di atas, diperoleh nilai koefisien determinasi $\left(R^{2}\right)$ sebesar 0,863 , hal ini menunjukkan bahwa model mampu menjelaskan hubungan antara $X_{1}, X_{2}, X_{3}$, $\mathrm{X}_{4}$ dengan $\mathrm{Y}$ sebesar $86,3 \%$.

b) Uji statistik F

Pengujian ini dilakukan dengan membandingkan nilai $F_{\text {hitung }}$ dengan $F_{\text {tabel }}$. Syarat hipotesis dapat diterima apabila $F_{\text {hitung }} \geq F_{\text {tabel }}$. Berdasarkan pada model persamaan regresi diatas diperoleh nilai $F_{\text {hitung }}$ sebesar 17,41 , sementara dengan $\alpha$ $=5 \%$ dan derajat kebebasan $(\mathrm{df}=3,45)$ diperoleh nilai $F_{\text {tabel }}$ sebesar 2,81. Dengan demikian maka $F_{\text {hitung }}>F_{\text {tabel }}$ atau 17,41 > 2,81, sehingga dapat disimpulkan bahwa secara simultan variabel bebas $\left(\mathrm{X}_{1}, \mathrm{X}_{2}\right.$, dan $\mathrm{X}_{3}$ ) berpengaruh terhadap $\mathrm{Y}$.

c) Uji t

Pengujian dengan membandingkan nilai probabilitas ( $p$-value) dengan probabilitas ( $\alpha$ ) 0.05 . Apabila nilai probabilitas ( $p$ value $) \leq 0.05$, maka $\mathrm{H}_{1}$ diterima dan $\mathrm{H}_{0}$ ditolak atau terdapat pengaruh yang signifikan dari variabel independen terhadap variabel dependen secara parsial.

\section{KESIMPULAN DAN SARAN}

\section{Kesimpulan}

Berdasarkan perhitungan tabel model estimasi fixed effect dan model persamaan regresi di atas, maka diperoleh sebagai berikut:

a. Nilai $\mathrm{X}_{1}$ (Current Ratio) dengan signifikansi $0,6654>0.05$, sehingga terbukti bahwa variabel $\mathrm{X}_{1}$ secara parsial tidak berpengaruh terhadap nilai Y (Return on Invesment).

b. Nilai $\mathrm{X}_{2}$ (Working Capital Turn Over Ratio) dengan signifikansi 0,1009>0.05 sehingga terbukti bahwa variabel $\mathrm{X}_{2}$ secara
Volume 9, Nomor 02, September 2017

parsial berpengaruh terhadap nilai $\mathrm{Y}$ (Return on Invesment) tetapi tidak signifikan.

c. Nilai $\mathrm{X}_{3}$ (Current Assets to Total Assets Ratio) dengan signifikasi 0,0956>0.05 sehingga terbukti bahwa variabel $\mathrm{X}_{3}$ secara parsial berpengaruh terhadap nilai $\mathrm{Y}$ (Return on Invesment) tetapi tidak signifikan.

d. Nilai $\mathrm{X}_{4}$ (Current Liabilities to Total Assets Ratio) dengan signifikansi 0,0047 0.05 sehingga terbukti bahwa variabel $\mathrm{X}_{3}$ secara parsial tidak berpengaruh terhadap nilai $\mathrm{Y}$ (Return on Invesment).

\section{Saran}

Sesuai dengan hasil penelitian, maka beberapa saran potensial penulis ajukan sebagai berikut

1. Perlu adanya peningkatan performance current assets agar nantinya nilai current ratio lebih baik lagi sehingga nilai current ratio tersebut lebih baik dapat digunakan sebagai indikator untuk mengetahui pengaruh kondisi modal kerja perusahaan terhadap profitabilitas perusahaan (Return on Invesment).

2. Perlu adanya peningkatan performance perusahaan dalam hal perubahan Working Capital Turn Over Ratio yang lebih baik agar nantinya membantu stakeholder untuk mengetahui kondisi kinerja modal kerja perusahaan dalam mempengaruhi profitabilitas perusahaan (Return on Invesment).

3. Perlu adanya peningkatan performance perusahaan dalam hal perubahan current assets to total assets ratio agar nantinya membantu stakeholder untuk mengetahui kondisi modal kerja perusahaan dalam mempengaruhi profitabilitas perusahaan (Return on Invesment).

4. Perusahaan mempertahankan kondisi current liabilities to total assets ratio bahkan harus menurunkan nilai current liabilities sehingga nantinya kondisi modal kerja perusahaan lebih baik lagi dalam peningkatan profitabilitas perusahaan. Selain itu, perlu adanya dibuatnya performance perusahaan dalam hal perubahan current liabilities to total 
Hermansyah, Pengaruh Kondisi Modal Kerja Terhadap Profitabilitas...

assets ratio agar nantinya membantu stakeholder untuk mengetahui kondisi modal kerja perusahaan dengan tolak ukur dari perubahan struktur komponen hutang lancar terhadap total aktiva perusahaan dan pengaruhnya dari perubahan struktur komponen hutang lancar tersebut terhadap profitabilitas perusahaan (Return on Invesment).

5. Bagi penelitian selanjutnya. Pertama, pemilihan sampel penelitian sebaiknya dilakukan secara random dan jumlah sampel lebih diperbanyak lagi agar tercipta distribusi data yang lebih baik. Kedua, sebaiknya dipilih sektor usaha lain agar nantinya dapat diketahui seberapa besar pengaruh kondisi modal kerja terhadap profitabilitas perusahaan pada sektor selain industri manufaktur.

\section{DAFTAR PUSTAKA}

Abdul Raheman \& Mahamed Nasr. 2007. Working Capital Management and Profitability - Case of Pakistani Firms. International of Business Research Papers. Vol.3 No.1 March 2007. pp. $279-300$.
Riyanto, Bambang. 2007. Dasar-Dasar Pembelanjaan Perusahaan, Yogyakarta : BPFE.

Robert Ang. 2007. Buku Pintar Pasar Modal Indonesia. Jakarta : Mediasoft Indonesia.

Sawir, Agnes. 2010. Analisa Kinerja Keuangan dan Pembelanjaan Perusahaan, Cetakan Kelima, Jakarta : PT. Gramedia Pustaka Utama.

Sundjaja, Ridwan, S \& Inge, Barlian. 2009. Manajemen Keuangan Satu, Jakarta : PT. Prehallindo.

Weston, J. Fred \& Thomas E Coopeland. 2010. Manajemen Keuangan, terjemahan JakaWasana dan Kibrandoko, Jakarta : Erlangga.

Winarno, Wing Wahyu. 2011. Analisis Ekonometrika dan Statistika Dengan Eviews. Edisi Ketiga. Yogyakarta : UPP STIM YKPN

Internet : $\underline{\text { http://www.idx.co.id }}$ 